\title{
Gated auditory speech perception: effects of listening conditions and cognitive capacity
}

\author{
Shahram Moradi ${ }^{*}$, Björn Lidestam ${ }^{2}$, Amin Saremi ${ }^{3,4}$ and Jerker Rönnberg ${ }^{1}$ \\ 1 Linnaeus Centre HEAD, The Swedish Institute for Disability Research, Department of Behavioral Sciences and Learning, Linköping University, Linköping, Sweden \\ 2 Department of Behavioral Sciences and Learning, Linköping University, Linköping, Sweden \\ ${ }^{3}$ Division of Technical Audiology, Department of Clinical and Experimental Medicine, Linköping University, Linköping, Sweden \\ ${ }^{4}$ Cluster of Excellence "Hearing4all," Department for Neuroscience, Computational Neuroscience Group, Carl von Ossietzky University of Oldenburg, Oldenburg, \\ Germany
}

Edited by:

Mari Tervaniemi, University of Helsinki, Finland

\section{Reviewed by:}

Mireille Besson, Institut de

Neurosciences Cognitives de la

Meditarranée, France

Oded Ghitza, Boston University, USA

\section{${ }^{*}$ Correspondence:}

Shahram Moradi, Linnaeus Centre HEAD, Department of Behavioral Sciences and Learning, Linköping University, SE-581 83 Linköping, Sweden

e-mail: shahram.moradi@liu.se
This study aimed to measure the initial portion of signal required for the correct identification of auditory speech stimuli (or isolation points, IPs) in silence and noise, and to investigate the relationships between auditory and cognitive functions in silence and noise. Twenty-one university students were presented with auditory stimuli in a gating paradigm for the identification of consonants, words, and final words in highly predictable and low predictable sentences. The Hearing in Noise Test (HINT), the reading span test, and the Paced Auditory Serial Attention Test were also administered to measure speech-in-noise ability, working memory and attentional capacities of the participants, respectively. The results showed that noise delayed the identification of consonants, words, and final words in highly predictable and low predictable sentences. HINT performance correlated with working memory and attentional capacities. In the noise condition, there were correlations between HINT performance, cognitive task performance, and the IPs of consonants and words. In the silent condition, there were no correlations between auditory and cognitive tasks. In conclusion, a combination of hearing-in-noise ability, working memory capacity, and attention capacity is needed for the early identification of consonants and words in noise.

\section{Keywords: gating paradigm, auditory perception, consonant, word, final word in sentences, silence, noise}

\section{INTRODUCTION}

Previous studies have attempted to establish isolation points (IPs), that is, the initial portion of a specific acoustic signal required for the correct identification of that signal, in silent conditions (see Grosjean, 1980). An IP refers to a given point in the total duration of a speech signal (i.e., a word) that listeners are able to correctly guess the identity of that signal with no change in their decision after hearing the reminder of that signal after that given point. In the present study, we investigated the IPs of different types of spoken stimuli (consonants, words, and final words in sentences) in both silence and noise conditions, in order to estimate the extent to which noise delays identification. In addition, a cognitive hearing science perspective was used to evaluate the relationships between explicit cognitive variables (working memory and attentional capacities), speech-in-noise perceptual ability, and IPs of spoken stimuli in both silence and noise.

\section{THE INITIAL PORTION OF STIMULI REOUIRED FOR CORRECT IDENTIFICATION OF CONSONANTS, WORDS, AND FINAL WORDS IN SENTENCES CONSONANT IDENTIFICATION}

The specific combined features of place (the place in the vocal tract that an obstruction occurs), manner (the configuration of articulators, i.e., tongue or lips, when producing a sound), and voicing (absence or presence of vocal fold vibration) constitute a given consonant. Listeners can correctly identify a consonant when these particular features are available (Sawusch, 1977). Smits (2000) reported that the location and spread of features for stops, fricatives, and nasals are highly variable. In a French gatingparadigm study, Troille et al. (2007) showed that for a $120-\mathrm{ms} / \mathrm{z} /$ consonant, identification occurred about $92 \mathrm{~ms}$ before its end.

Noise in combination with the acoustic features of consonants may cause a perceptual change, such that the noise may be morphed together with the consonant, masking or adding consonant features, thereby changing the percept into another consonant (Miller and Nicely, 1955; Wang and Bilger, 1973; Phatak and Allen, 2007). As a result, the number of correctly identified consonants in noise is reduced (Wang and Bilger, 1973; Phatak and Allen, 2007). Phatak and Allen (2007) reported that consonant identification in white noise falls into three categories: a set of consonants that are easily confused with each other (e.g., /f $\mathrm{v} \mathrm{b}$ $\mathrm{m} /$ ), a set of consonants that are intermittently confused with each other (e.g., /n p g k d/), and a set of consonants that are hardly ever confused with each other (e.g., /t s z /). Based on the results of Phatak and Allen (2007) showing that noise impacts differently on different consonants, one may predict that the influence of noise should be larger for the consonants that are more easily confused with each other. Furthermore, the signal-to-noise ratio (SNR) required for the identification of consonants varies across consonants (Miller and Nicely, 1955; Woods et al., 2010). We therefore expect that, compared with silence, noise will generally delay the correct identification of consonants. 


\section{IDENTIFICATION OF ISOLATED WORDS}

Word identification requires an association between an acoustic signal and a lexical item in long-term memory (Lively et al., 1994). According to the cohort model (Marslen-Wilson, 1987), initial parts of a speech signal activate several words in the lexicon. As successively more of the acoustic signal is perceived, words in the lexicon are successively eliminated. Word identification occurs when only one word candidate is left to match the acoustic signal. Gating paradigm studies have generally demonstrated that word identification occurs after a little more than half of the duration of the whole word (Grosjean, 1980; Salasoo and Pisoni, 1985).

Identification of isolated words is poorer in noise than in silence (Chermak and Dengerink, 1981; Dubno et al., 2005). As the main constituents of words, some vowels (Cutler et al., 2005) and consonants (Woods et al., 2010) are highly affected by noise. For instance, Parikh and Loizou (2005) showed that whereas /o/ had the lowest identification score in a noisy condition compared to other vowels, /i/ had the highest identification score. Presentation of $/ \mathrm{o} /$ in a noisy condition activated perception of other vowels like /U/. Based on the findings of Parikh and Loizou (2005), noise has differential effects on identification of different vowels (similar to consonants), meaning that the combination of vowels and consonants with noise activates other vowels and consonants, which disturbs the mapping of the input signal with the representations in the mental lexicon. We expect that the addition of these noise-induced extra-activated candidates will delay IPs, as more acoustic information will be needed to map the signal with the phonological representations in the mental lexicon. In addition, noise is likely to be detrimental to the success of this mapping, as it results in a lower intelligibility.

\section{IDENTIFICATION OF FINAL WORDS IN SENTENCES}

When words are presented in sentences, listeners can benefit from the syntactic structure (Miller and Isard, 1963) and semantic context in congruent sentences (Kalikow et al., 1977), which in turn can speed up target word identification in comparison with word-alone presentation (Miller et al., 1951; Grosjean, 1980; Salasoo and Pisoni, 1985). This improvement in word identification occurs because contextual factors inhibit the activation of other lexical candidates that are a poorer fit for the linguistic context (Marslen-Wilson, 1987).

The predictability of sentences is a key variable for final word identification in sentences. The estimation of word predictability is derived from a "cloze task procedure" (Taylor, 1953) when subjects are asked to perform a sentence completion task with the final word is missing. For instance, the word "bird" in the sentence "a pigeon is a kind of bird" is an example of a highly predictable word but in the sentence "she pointed at the bird" it is as an example of a low predictable word. It should be noted that the highly predictable and low predictable words differ from anomalous words, wherein words are randomly substituted. Regarding the example above, the word "bird" is incongruous in the sentence "The book is a bird." Final words are easier to identify in meaningful sentences than in semantically anomalous sentences (Miller and Isard, 1963). Highly predictable sentence contexts enhance one's capability to disambiguate final words compared with low predictable sentence contexts (Kalikow et al., 1977).
Prior context facilitates word identification in noise (e.g., Grant and Seitz, 2000); when highly predictable sentences are heard, the auditory thresholds for word identification are lowered (Sheldon et al., 2008; Benichov et al., 2012). Final word identification in noise is different from tests on sentence comprehension in noise (e.g., the Hearing in Noise Test [HINT], Nilsson et al., 1994; Hällgren et al., 2006). The latter requires the listener to repeat the entirety of sentences, in an adaptive procedure. However, final word identification tasks are usually presented at a constant SNR, and require participants to predict which word will come at the end of the sentence, and therefore demands less cognitive effort. They thus differ in the retrieval demands they put on explicit resources such as working memory (Rönnberg et al., 2013).

\section{COGNITIVE DEMANDS OF SPEECH PERCEPTION IN SILENCE AND NOISE}

According to the Ease of Language Understanding (ELU) model (Rönnberg et al., 2008), working memory acts as an interface between incoming signals and the mental lexicon. Working memory enables the storage and processing of information during online language understanding. In this model, the incoming signal automatically feeds forward at a sub-lexical (syllable) level in rapid succession to match the corresponding phonological representation in the mental lexicon (cf. Poeppel et al., 2008; Rönnberg et al., 2013). This process of syllabic matching is assumed to demand less working memory capacity for normal-hearing people under optimum listening conditions, resulting in rapid and implicit online language processing. However, if the incoming signal is poorly specified or distorted (e.g., in noisy conditions), a mismatch (or non-match, cf. Rönnberg et al., 2013 for a detailed discussion on the match/mismatch issue) will occur with the phonological representation in the mental lexicon. The rapid and implicit process of lexical access is temporarily disturbed under such conditions. In such cases, explicit and deliberate cognitive processes (i.e., inference-making and attentional processing) are invoked to compensate for this mismatch in order to detect or reconstruct the degraded auditory signal. Previous studies have shown that attentional and inference-making processes greatly depend on working memory capacity (Kane and Engle, 2000; De Neys et al., 2003). Independent support for the ELU model (Rönnberg et al., 2008) comes from studies showing two auditory cortical mechanisms of processing: an automatic segregation of sounds, and an attention-demanding network that analyzes the acoustic features of incoming auditory signals (Petkov et al., 2004; Snyder et al., 2006, see also Rönnberg et al., 2013). Röer et al. (2011) reported that auditory distraction disturbs the automatic connection of auditory stimuli to the phonological representations in long-term memory.

Previous research has supported the notion that working memory capacity is crucial for speech perception in adverse listening conditions (for recent reviews, see Rönnberg et al., 2010, 2013; Mattys et al., 2012). Unfavorable listening conditions place higher demands on working memory processing (Lunner et al., 2009), and less resources are therefore available for the storage of incoming signals (Rabbitt, 1968).

Attentional capacity of listeners is also a cognitive function that plays a critical role in speech perception under degraded listening 
conditions (Carlyon et al., 2001; Shinn-Cunningham and Best, 2008; Mesgarani and Chang, 2012). In degraded listening conditions, attention is focused on the signal's frequency (Dai et al., 1991), the spatial spectrum (Mondor et al., 1998; Boehnke and Phillips, 1999), one channel of information (Conway et al., 2001), or the switching between channels of information (Colflesh and Conway, 2007). This focus of attention enables the segregation of different types of auditory competitors for speech understanding and subsequent memory encoding (cf. Rönnberg et al., 2008, 2013; Sörqvist and Rönnberg, 2012; Sörqvist et al., 2012).

\section{THE PRESENT STUDY}

The general purpose was to study how large the initial portion of the stimulus needs to be in order for correct identification, and therefore how demanding the perception is, as an effect of how easy the signal is to discriminate and predict. IPs refer to how large the initial portion of the entire signal that is needed for correct identification. Hence, IPs specify how much of the entire signal is required for correct identification, and thereby how quickly the stimuli are identified. It can be assumed that the identification of stimuli is less demanding if the stimuli are identified earlier. Therefore, IPs should allow us to estimate the amount of cognitive demand needed for correct identification of speech stimuli in silence versus in noise, which lowers discriminability, and under different levels of predictability (e.g., due to lexical and sentential context). In turn, this should be reflected in correlations with measures of explicit cognitive functions.

The general purpose encompasses two aims. The first aim was to compare the IPs of different types of spoken stimuli (consonants, words, and final words in sentences) in both silence and noise conditions, using a gating paradigm (Grosjean, 1980). Subordinate to this aim were two more specific research questions. Firstly, how much does noise generally affect IPs? It was assumed that masking speech with noise would generally delay IPs. Secondly, how does noise affect IPs when considering linguistic (i.e., lexical and sentential) context? In consonant identification, compensatory lexical and contextual resources were not available in the present study. Therefore, listeners had to identify the consonants based on critical cues of their acoustic properties, distributed across their entire durations. In word identification, the masking of consonants and vowels with noise is likely to diminish one's ability to identify the words, or to misdirect the listener to interpret them as other words. However, lexical knowledge may aid listeners (Davis and Johnsrude, 2007), although noise is likely to delay IPs for words (as well as for consonants). In final word identification in sentences, we therefore assumed that the contextual and semantic information inherent in naturalistic sentences would speed up the identification of target words, even in noise, compared to words presented in isolation. Words positioned at the end of sentences that had either a low predictable or a high predictable semantic context were also compared, so as to further test the benefit of contextual support.

The second aim was to investigate the relationship between explicit cognitive functions (capacities of working memory and attention) and the IPs of different types of spoken stimuli (consonants, words, and final words in sentences) in both silence and noise conditions. On the basis of the ELU model (e.g., Rönnberg et al., 2008, 2013) as well as several independent empirical studies (e.g., Petkov et al., 2004; Snyder et al., 2006; Foo et al., 2007; Rudner et al., 2009, 2011), we predicted that significant correlations would exist between performance in tests of attention and working memory and IPs of gated stimuli in noise, but to a relatively lesser extent in silence.

\section{METHODS}

\section{Participants}

Twenty-one university students (12 males and 9 females) at Linköping University, Sweden were paid to participate in this study. Their ages ranged from 20 to 33 years ( $M=24.6$ years). All of the students were Swedish native speakers that spoke Swedish at home and at the university. According to the Swedish educational system, the students (or pupils) learn English and at least one another language (e.g., German, French, Spanish) in school. The participants reported having normal hearing, normal vision (or corrected-to-normal vision), and no psychological or neurological pathologies. The participants gave consent, pursuant to the ethical principles of the Swedish Research Council (Etikregler för humanistisk-samhällsvetenskaplig forskning, n.d.), the Regional Ethics Board in Linköping, and Swedish practice for research on normal populations.

\section{MEASURES}

\section{Gating speech tasks}

Consonants. The study employed 18 Swedish consonants presented in vowel-consonant-vowel syllable format (/aba, ada, afa, aga, aja, aha, aka, ala, ama, ana, ana, apa, ara, aţa, asa, afa, ata, $\mathrm{ava} /$ ). The gate size for consonants was set at $16.67 \mathrm{~ms}$. The gating started after the first vowel /a/ and right at the beginning of the consonant onset. Hence, the first gate included the vowel /a/ plus the initial $16.67^{1} \mathrm{~ms}$ of the consonant, the second gate gave an additional $16.67 \mathrm{~ms}$ of the consonant (a total of $33.34 \mathrm{~ms}$ of the consonant), and so on. The minimum, average, and maximum total duration of consonants were 85,198 , and $410 \mathrm{~ms}$, respectively. The maximum number of gates required for identification was 25 . The consonant gating task took between 40 and $50 \mathrm{~min}$ to complete.

Words. The words in this study were chosen from a pool of Swedish monosyllabic words in a consonant-vowel-consonant format that had average to high frequencies according to the Swedish language corpus PAROLE (2011). Forty-six of these words (all nouns) were chosen and divided into two lists (A and B) comprising 23 words each. Both lists were matched in terms of onset phonemes and neighborhood size (i.e., lexical candidates that shared similar features with the target word). Each word used in the present study had a small to average numbers of neighbors (3-6 alternative words with the same pronunciation of the

\footnotetext{
${ }^{1}$ The rationale for setting gate size to $16.67 \mathrm{~ms}$ came from audiovisual gating tasks (See Moradi et al., 2013), to get the same gate size for both conditions (i.e., audiovisual and auditory modalities). By using 120 frames/s for recording visual speech stimuli, $8.33 \mathrm{~ms}$ of a visual stimulus is available in each frame $(1000 \mathrm{~ms} / 120 \mathrm{frame} / \mathrm{s}=8.33 \mathrm{~ms})$. Multiplying 8.33 by 2 (frames), there is $16.67 \mathrm{~ms}$ (Please see Lidestam, 2014, for detailed information).
} 
first two phonemes, e.g., the target word /dop/ had the neighbors /dog, dok, don, dos/). For each participant, we presented one list in silence and the other in noise. The presentation of words was randomized across participants. Participants in the pilot studies complained that word identification with the gate size used for consonants $(16.67 \mathrm{~ms})$ led to fatigue and a loss of motivation. Therefore, a doubled gate size of $33.3 \mathrm{~ms}$ was used for word identification and also we presented the first phoneme (consonant) of each word as a whole, and gating was started from the onset of the second phoneme (vowel) in order to prevent any exhaustion for the participants. The minimum, average, and maximum duration of words were 548, 723, and $902 \mathrm{~ms}$, respectively. The maximum number of gates required for identification was 21 . The word gating task took between 35 and $40 \mathrm{~min}$ to complete.

Final Words in Sentences. There were two types of sentences in this study, which differed according to how predictable the last word in each sentence was: sentences with a highly predictable (HP) last word (e.g., "Lisa gick till biblioteket för att låna en bok"; "Lisa went to the library to borrow a book") and sentences with a low predictable (LP) last word (e.g., "I förorten finns en fantastisk dal"; "In the suburb there is a fantastic valley"). The last (target) word in each sentence was always a monosyllabic noun.

To begin with, we constructed a battery of sentences that had differing predictability levels. This was followed by three consecutive pilot studies for the development of HP and LP sentences. First, the preliminary versions of sentences were presented in written form to some of the staff members at Linköping University in order to grade the predictability level of the target words in each sentence, from 0 (unpredictable) to 10 (highly predictable), and to obtain feedback on the content of the sentences in order to refine them. The sentences with scores over 7 were used as HP sentences, and those with scores below 3 were used as LP sentences. The rational for criterion below 3 for final words in LP sentences was based on our interest to have a minimum predictability in the sentences in order to separate identification of final words in LP sentences from identification of final words in anomalous sentences or identification of isolated-words. We then revised the sentences on the basis of the feedback. A second pilot study was conducted on 15 students at Linköping University to grade the predictability level of the revised sentences in the same way (from 0 to 10). Once again, the sentences with scores over 7 were used as HP sentences, and those with scores below 3 were used as LP sentences. In a third pilot study, the remaining sentences were presented to another 15 students to grade their predictability level. Again, we chose the sentences with scores over 7 as HP sentences, and the sentences with scores below 3 as LP sentences.

In total, there were 44 sentences (22 HP sentences and $22 \mathrm{LP}$ sentences, based on the last word in each sentence). The gating started from the onset of the first phoneme of the target word. Because of the supportive effects of context on word identification, and based on the pilot data, we set the gate size at $16.67 \mathrm{~ms}$ to optimize time resolution. The average duration of each sentence was $3030 \mathrm{~ms}$. The minimum, average, and maximum duration for target words at the end of sentences were 547, 710, and $896 \mathrm{~ms}$, respectively. The maximum number of gates required for identification was 54 . The gating final-word in sentence task took between 25 and $30 \mathrm{~min}$ to complete.

\section{Hearing in Noise Test}

We used a Swedish version of the HINT (Hällgren et al., 2006), adapted from Nilsson et al. (1994), to measure the hearing-innoise ability of the participants. The HINT sentences consisted of three-to-seven word everyday sentences with fluctuating $\pm 2 \mathrm{~dB}$ SNR. The sentences were normalized for naturalness, difficulty, and reliability. The sentences were read aloud by a female speaker. In the present study, we used one list consisting of 10 sentences in the practice test, and one list consisting of 20 sentences in the main test to estimate SNR required for $50 \%$ correct performance (i.e., correct repetition of $50 \%$ of the sentences). The HINT took about $10 \mathrm{~min}$ per participant to complete.

\section{Cognitive Tests}

Reading Span Test. The reading span test was designed to measure working memory capacity. The task requires the retention and recall of words while reading simple sentences. Baddeley et al. (1985) developed one such test based on the technique devised by Daneman and Carpenter (1980) in which sentences are presented visually, word by word, on a computer screen.

Several small lists of short sentences were presented to participants on the screen. Each sentence had to be judged as to its semantic correctness. Half of the sentences were semantically correct, and the other half were not (e.g., "Pappan kramade dottern"; "The father hugged his daughter" or "Räven skrev poesi"; "The fox wrote poetry") (Rönnberg et al., 1989; Rönnberg, 1990). The test began with two-sentence sets, followed by three-sentence sets, and so forth, up to five-sentence sets. Initially, participants were asked to press the "L" key if the sentence made sense or the " $\mathrm{S}$ " key for illogical sentences. After the set had been presented, participants were then required to recall either the first or final words of each sentence (e.g., "Pappan" and "Räven"; or "dottern"; and "poesi"), in the correct serial presentation order. Participants had about $3 \mathrm{~s}$ to press the "L" or " $\mathrm{S}$ " keys before the next sentence appeared. The computer instructed the participants to repeat either the first words or the last words of each sentence in the current set by typing them. The reading span score for each participant was equivalent to the total number of correctly recalled words across all sentences in the test, with a maximum score of 24 . The reading span test took about 15 min per participant to complete.

The Paced Auditory Serial Addition Test (PASAT). The PASAT was initially designed to estimate information processing speed (Gronwall, 1977), but it is widely considered a test of attention (for a review, see Tombaugh, 2006). The task requires subjects to listen to a series of numbers (1-9), and to add consecutive pairs of numbers as they listen. As each number is presented, subjects must add that number to the previous number. For example, the following sequence of numbers is presented, one number at a time, every 2 or $3 \mathrm{~s}: 2,5,7,4$, and 6 . The answers are: 7, 12, 11, and 10 . The test demands a high level of attention, particularly if the numbers are presented quickly. In this study, we used a version of the PASAT in which digits were presented at an interval of 
either 2 or $3 \mathrm{~s}$ (Rao et al., 1991), referred to as the PASAT 2 and the PASAT 3, respectively. Participants started with the PASAT 3, followed by the PASAT 2, with a short break between the two tests. The total number of correct responses (maximum possible $=60$ ) at each pace was computed. The PASAT took about $15 \mathrm{~min}$ per participant to complete.

\section{Preparation of gating tasks and procedure}

A female speaker with clear enunciation and standard Swedish dialect read all of the items with normal intonation at a normal speaking rate in a quiet studio. Each item (consonant, word, or sentence) was recorded several times. We selected the item with the most natural intonation and clearest enunciation. Items were matched for sound level intensity. The sampling rate of the recording was $48 \mathrm{kHz}$, and the bit depth was 16 bits.

The onset and offset times of each recorded stimulus were marked in order to segment different types of stimuli. For each target, the onset time of the target was located as precisely as possible by inspecting the speech waveform (with Sound Studio 4 software) and using auditory feedback. The onset time was defined as the point where the signal amplitude ascended from the noise floor, according to the spectrograms in the Sound Studio 4 software. Each segmented section was then edited, verified, and saved as a ".wav" file. The gated stimuli were checked to eliminate click sounds. The root mean square value was computed for each stimulus waveform, and the stimuli were then rescaled to equate amplitude levels across the stimuli. A steady-state broadband noise, from Hällgren et al. (2006), was resampled and spectrally matched to the speech signals for use as background noise. The onset and offset of noise were simultaneous to the onset and offset of the speech signals.

The participants were tested individually in a quiet room. They were seated at a comfortable distance from a MacBook Pro (with Mac OS 10.6.7). Matlab (R2010b) was used to gate and present the stimuli binaurally through headphones (Sennheiser HDA200).

Participants received written instructions about the conditions for the different tasks (consonants, words, and final words in sentences), and performed several practice trials. In the practice trial, the sound level of the presentation was adjusted individually for each participant to a comfort level (approximately 60-65 dB). This sound level was used with no change in adjustment for that participant in both silent and noise conditions. In the noise condition (steady-state noise), the SNR was set at $0 \mathrm{~dB}$, which was based on the findings of a pilot study using the current set of stimuli. During the practice session, the experimenter demonstrated how to use the keyboard to respond during the actual test. The participants were told that they would hear only part of a spoken target and would then hear progressively more. Participants were told to attempt identification after each presentation, regardless of how unsure they were about the identification of the stimulus, but to avoid random guessing. The participants were instructed to respond aloud and the experimenter recorded their responses. When necessary, the participants were asked to clarify their responses. The presentation of gates continued until the target was correctly identified on six consecutive presentations. If the target was not correctly identified, then the presentation continued until the entire target was disclosed, even if six or more consecutive responses were identical. Then, the experimenter started the next trial. When a target was not identified correctly, even after the whole target had been presented, its total duration plus one gate size was used as an estimate of the IP (cf. Elliott et al., 1987; Walley et al., 1995; Metsala, 1997; Hardison, 2005; Moradi et al., 2013). The rationale for this estimated IP was based on the fact that it was possible for participants to give correct responses at the last gate of a given target; hence, calculating an IP equal to the total duration of that target for two correct responses (even when late) and wrong responses would not be appropriate. No specific feedback was given to participants at any time during the session, except for general encouragement. Furthermore, there was no time pressure for responding to what was heard.

Each subject performed all of the gating tasks (consonants, words, and final words in sentences) in one session. All participants started with the identification of consonants task, followed by words task, and ended with the final words in sentences task. The type of condition (silence or noise) was counterbalanced across participants, such that half of the participants started with consonant identification in silence and then proceeded to consonant identification in noise, and vice versa for the other half of the participants. The order of items within each type of stimulus material (consonants, words, and sentences) varied between participants.

The full battery of gating tasks took 100-120 min per participant to complete. All of the tasks were performed in one session, but short rest periods were included to prevent fatigue. In the second session, the HINT, the reading span test, and the PASAT were administered. The order of the tests was counterbalanced across the participants. The second session took about $40 \mathrm{~min}$ per participant to complete.

\section{RESULTS}

\section{GATING SPEECH TASKS}

Figure 1 shows the mean IPs of consonants presented in both silence and noise conditions. Appendices A and B are confusion matrices for the 18 Swedish consonants presented in silence and noise, respectively. The values in the confusion matrices were extracted from correct and incorrect responses across all gates in the consonant gating paradigm tasks performed either in silence and noise. Figure 2 shows the mean IPs for the gated speech tasks in both silence and noise conditions.

A Two-Way repeated-measure analysis of variance (ANOVA) was conducted to compare the mean IPs of the gated tasks (consonants, words, final words in LP sentences, and final words in HP sentences) in silence and noise. The results showed a main effect of the listening condition, $F_{(1,20)}=213.54, p<0.001$, $\eta p^{2}=0.91$; a main effect of the gated tasks, $F_{(1.23,24.54)}=$ 909.27, $p<0.001, \eta p^{2}=0.98$; and an interaction between listening condition and gated tasks, $F_{(1.58,31.58)}=49.84, p<0.001$, $\eta p^{2}=0.71$. Four planned comparisons showed that the mean IPs of consonants in silence $(M=101.78, S D=11.47)$ occurred earlier than in noise $(M=166.14, S D=26.57), t_{(20)}=12.35$, $p<0.001, d=3.20$. In addition, the mean IPs of words in silence $(M=461.97, S D=28.08)$ occurred earlier than in noise $(M=670.51, S D=37.64), t_{(20)}=17.73, p<0.001, d=5.49$. The mean IPs of final words in LP sentences in silence $(M=$ $124.99, S D=29.09)$ were earlier than in noise $(M=305.18$, $S D=121.20), t_{(20)}=7.67, p<0.001, d=2.56$. In addition, the 


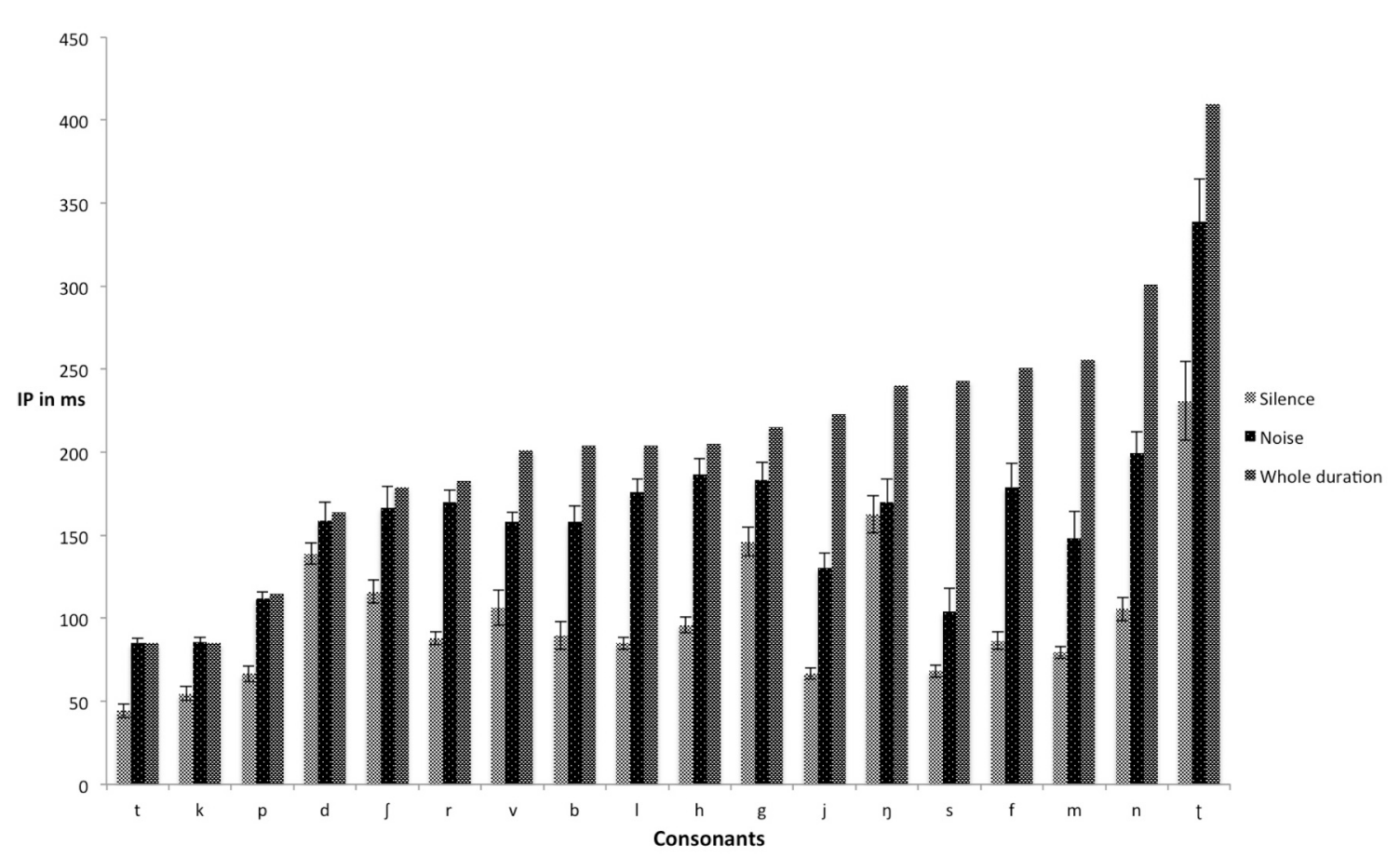

FIGURE 1 | Mean IPs (ms) for consonants in both silence and noise (with accompanying standard errors). IP, isolation point.

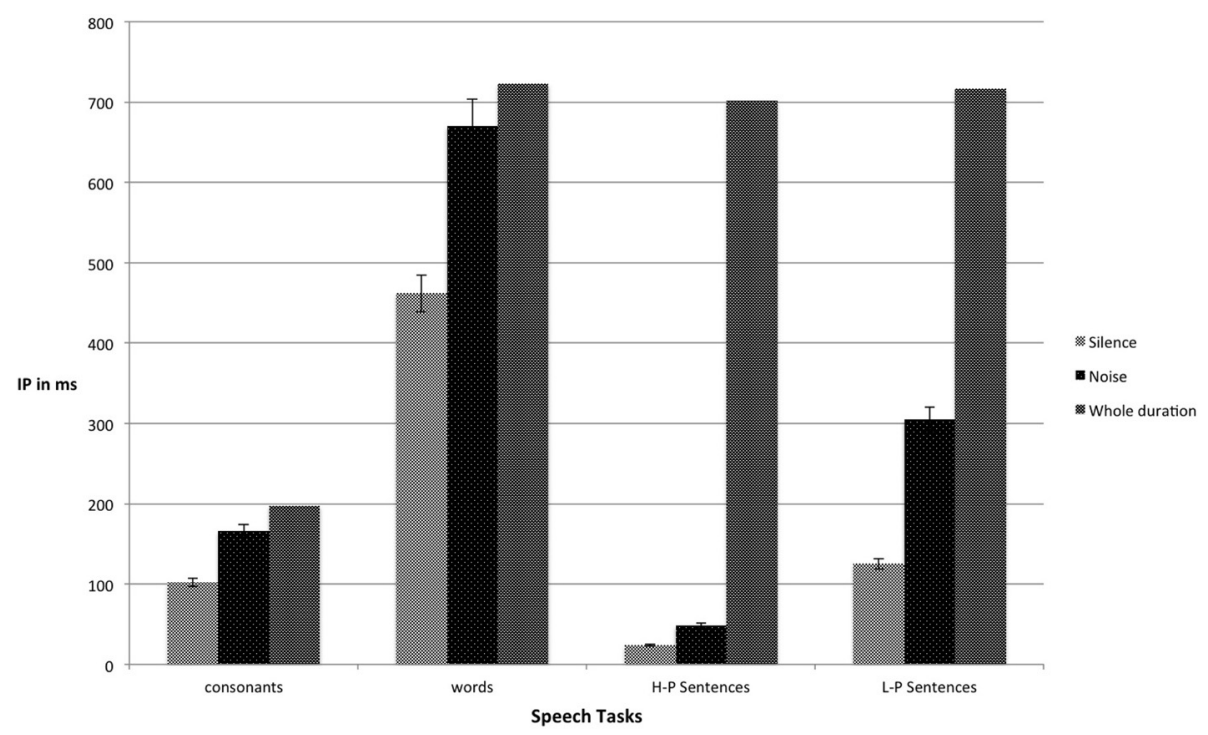

FIGURE 2 | Mean IPs (ms) for consonants, words, and final words in HP and LP sentences, in both silence and noise (with accompanying standard errors). IP, isolation point; HP, highly predictable; LP, low predictable.

mean IPs of final words in HP sentences in silence $(M=23.96$, $S D=3.31)$ occurred earlier than in noise $(M=48.57, S D=$ $23.01), t_{(20)}=4.96, p<0.001, d=1.43$. We also analyzed our data by including only correct responses. The results showed that the mean IPs for consonants were $98.26(S D=7.98) \mathrm{ms}$ in silence and $137.83(S D=21.95) \mathrm{ms}$ in noise. In words, the mean IPs in silence were $456.31(S D=21.49) \mathrm{ms}$ in silence and $505.89(S D=$
50.77) $\mathrm{ms}$ in noise. In final words in LP sentences, the mean IPs were $102.18(S D=20.86) \mathrm{ms}$ in silence and $114.94(S D=$ 22.03) $\mathrm{ms}$ in noise. In final words in HP sentences, the mean IPs were $23.86(S D=3.33) \mathrm{ms}$ in silence and $42.24(S D=15.24)$ $\mathrm{ms}$ in noise. When comparing the results from two methods of IP calculations (i.e., including error responses with whole IPs of target stimuli plus one gate size, vs. including correct responses 
only), there were subtle differences between IPs in silence; but greater differences in noise. For instance, when the IP calculation was based on correct responses only, the mean IPs for final word identification in sentences was $102.18 \mathrm{~ms}$ in silence and $114.94 \mathrm{~ms}$ in noise. However, when considering both correct and incorrect responses in the calculation of IPs for final word identification in sentences, the mean IPs became $124.99 \mathrm{~ms}$ in silence and $305.18 \mathrm{~ms}$ in noise. We therefore argue that the inclusion of error responses actually responses highlighted the interaction between noise and stimulus predictability (i.e., lexical, sentential, and semantic context), and that the interaction was logical and valid. In addition, the ANOVA on IPs only including correct responses showed the same pattern of results. There was a main effect of listening condition, $F_{(1,20)}=45.89, p<0.001, \eta p^{2}=$ 0.70 ; a main effect of the gated tasks, $F_{(1.68,33.49)}=3545.27, p<$ $0.001, \eta p^{2}=0.99$; and an interaction between listening condition and gated tasks, $F_{(1.55,30.91)}=6.10, p<0.01, \eta p^{2}=0.23$.

Table 1 reports the percentage of correct responses for each of the gated tasks performed in both silence and noise conditions. A Two-Way repeated-measures analysis (ANOVA) showed a main effect of listening condition, $F_{(1,20)}=223.41, p<0.001$, $\eta p^{2}=0.92$; a main effect of the gated tasks, $F_{(3,60)}=36.86, p<$ $0.001, \eta p^{2}=0.65$; and an interaction between listening condition and gated tasks, $F_{(3,60)}=33.24, p<0.001, \eta p^{2}=0.62$. Four planned comparisons showed that noise reduced the accuracy for the identification of consonants, $t_{(20)}=7.50, p<0.001, d=$ 2.21; words, $t_{(20)}=15.14, p<0.001, d=4.26$; final words in LP sentences, $t_{(20)}=4.28, p<0.001, d=1.10$; and final words in HP sentences, $t_{(20)}=2.90, p<0.009, d=1.51$.

\section{CORRELATIONS BETWEEN GATING SPEECH TASKS, THE HINT, AND THE COGNITIVE TESTS}

Table 2 shows the means responses of participants for the HINT, PASAT 3, PASAT 2, and the reading span test. The correlation matrix (Table 3) shows the Pearson correlations between the IPs of gated tasks in both silence and noise conditions (lower scores in the gated tasks reflect better function), the HINT scores (lower scores in the HINT reflect better function), and the reading span test and PASAT scores (higher scores in the reading span test and PASAT reflect better function). The PASAT 2 scores were significantly correlated with the HINT scores, the reading span test scores, IPs of consonants in noise, and IPs of words in noise. This finding suggested that lower IP scores for consonants and words in noise were usually associated with better performance on the HINT and PASAT 2. The reading span test scores were also significantly correlated with the HINT scores and IPs for

Table 1 | Identification accuracy for gating spoken stimuli.

\begin{tabular}{lcc}
\hline Type of gated stimuli & Silence mean (SD) & Noise mean (SD) \\
\hline Consonants & $97.4(3.8)$ & $70.1(17.5)$ \\
Words & $96.3(5.2)$ & $34.6(17.1)$ \\
HP Sentences & $94.8(7.7)$ & $85.7(8.0)$ \\
LP Sentences & $87.3(7.3)$ & $67.1(20.3)$ \\
\hline
\end{tabular}

SD, standard deviation; HP, highly predictable; LP, low predictable. consonants in noise, indicating that better performance on the reading span test was associated with better performance on the HINT and earlier IPs for consonants in noise. The HINT scores were significantly correlated with IPs for consonant and word identification in noise; the better the listeners performed on the HINT, the earlier they generally identified consonants and words in noise.

We also compared pairs of correlational coefficients in silence and noise (Table 4). The results showed that three pairwise correlations were significantly different from each other. We also tested if there is a difference between the means of the correlation coefficients of the two matrices (between the IPs and the scores of the cognitive tasks and the HINT, with $z$ transformed correlation coefficients). We therefore first put all correlation coefficients in the same (logical) direction. Then we tested the means difference with a paired two-tailed $t$ test. In this case, $n=12$, since we used the number of paired correlations as "individuals." The result was $t_{(10)}=3.64, p=0.005, d=1.05$, that is, a significant difference between the mean correlation coefficients for silence versus noise, with a large effect size. We argue that the data pattern, comparing correlations for the silent versus noisy conditions, shows a valid difference such that cognitive tests are generally more strongly correlated with IPs for consonants and words in the noisy conditions compared to the silent conditions. Thus, support for the validity of this conclusion comes from (a) the overall qualitative pattern of differences in correlation matrices, (b) from inferential statistics comparing pairwise correlations, and (c) from statistical comparison of the entire (pooled) correlation matrices.

\section{DISCUSSION HOW DOES NOISE GENERALLY AFFECT IPS?}

The results show that noise generally delayed the IPs for the identification of consonants, words, and final words in LP and HP sentences, which is in line with the predictions. Furthermore, our results demonstrate the advantage of IPs over accuracy especially in the silent condition. While there was a ceiling effect for identification of consonants, words, and final words in HP sentences in silence (over 95\% correct responses), there was substantial variation in their IPs.

\section{HOW DOES NOISE AFFECT IPS WHEN CONSIDERING LINGUISTIC (i.e., LEXICAL AND SENTENTIAL) CONTEXT? Consonants}

There was variation in the IPs of consonants, implying that the location of critical cues for their identification varies across

Table 2 | HINT, PASAT 3, PASAT 2, and reading span test results.

\begin{tabular}{lc}
\hline Type of task & Mean (SD) \\
\hline HINT & $-3.1(1.2)$ \\
PASAT 3 & $51.2(4.4)$ \\
PASAT 2 & $40.0(6.2)$ \\
Reading span test & $21.6(1.7)$ \\
\hline
\end{tabular}

HINT, Hearing in Noise Test; PASAT, Paced Auditory Serial Attention Test (digits are presented at an interval of 2 or $3 s$ ); $S D$, standard deviation. 
Table 3 | Correlation matrix for gating speech variables, HINT, and cognitive test results.

\begin{tabular}{|c|c|c|c|c|c|c|c|c|c|c|c|c|}
\hline & 1 & 2 & 3 & 4 & 5 & 6 & 7 & 8 & 9 & 10 & 11 & 12 \\
\hline 2. PASAT 3 & & & $0.51 *$ & $0.55^{*}$ & -.012 & -0.22 & 0.06 & 0.07 & 0.04 & -0.14 & -0.23 & -0.39 \\
\hline 4. RST & & & & & -0.19 & $-0.51^{*}$ & 0.23 & -0.30 & -0.21 & -0.41 & -0.35 & -0.42 \\
\hline 5. Consonant-S & & & & & & $0.44^{*}$ & -0.09 & 0.36 & -0.15 & 0.03 & 0.07 & 0.32 \\
\hline 8. Word-N & & & & & & & & & 0.16 & 0.27 & -0.16 & 0.16 \\
\hline 9. HP-S & & & & & & & & & & 0.33 & 0.15 & -0.04 \\
\hline 10. LP-S & & & & & & & & & & & $0.50 *$ & $0.56 * *$ \\
\hline 11. HP-N & & & & & & & & & & & & $0.58 * *$ \\
\hline 12. LP-N & & & & & & & & & & & & \\
\hline
\end{tabular}

HINT, Hearing in Noise Test; PASAT, Paced Auditory Serial Attention Test (digits are presented at an interval of 2 or 3 s); RST, Reading Span Test; Consonant-S, gated consonant identification in silence; Consonant- $N$, gated consonant identification in noise; Word-S, gated word identification in silence; Word-N, gated word identification in noise; HP-S, gated final word identification in highly predictable sentences in silence; LP-S, gated final word identification in low predictable sentences in silence; HP-N, gated final word identification in high predictable sentences in noise; LP-N, gated final word identification in low predictable sentences in noise. ${ }^{*} p<0.05 .{ }^{* *} p<0.01$.

Table 4 | Fisher's Z scores to compare correlation coefficients between silence and noise.

\begin{tabular}{lcccc}
\hline & Consonants & Words & $\begin{array}{c}\text { Final words } \\
\text { in HP }\end{array}$ & $\begin{array}{c}\text { Final words } \\
\text { in LP }\end{array}$ \\
\hline HINT & $-2.69^{*}$ & $-2.69^{*}$ & 0.26 & 0.09 \\
PASAT 3 & 0.91 & -0.03 & 1.02 & 1.23 \\
PASAT 2 & 1.56 & $2.18^{*}$ & -0.11 & 0.62 \\
Reading span test & 1.48 & 1.46 & 0.55 & 0.08 \\
\hline${ }^{*} p<0.05$. & & & &
\end{tabular}

consonants, corroborating the findings of Smits (2000). For instance, the time ratio in silence showed that $/ \mathrm{b} \mathrm{f} \mathrm{h} \mathrm{jl} \mathrm{m} \mathrm{n} \mathrm{s/}$ required roughly one-third and / $\mathrm{k} \mathrm{p} \int /$ required about twothirds of their full durations for identification. Noise extended the amount of time required for correct identification of consonants. Consonants in the noise condition required longer exposure to be identified because their critical features were masked. In our study, the accuracy rate for correct identification of consonants was about $97 \%$ in silence, which dropped to $70 \%$ in noise (Table 1). This is consistent with the findings of Apoux and Healy (2011), wherein listeners correctly identified $68 \%$ of consonants in speech-shaped noise at $0 \mathrm{~dB}$ SNR. Cutler et al. (2008) reported about $98 \%$ correct identification of consonants in quiet conditions, and about $80 \%$ in eight-talker babble noise. In addition, the results in the confusion matrix (Supplementary meterials) for identification of Swedish consonants show that at 0 SNR dB, /b $\mathrm{d} \mathrm{g} \mathrm{h} \mathrm{k} \mathrm{r} \mathrm{t \int} \mathrm{t/} \mathrm{are} \mathrm{often} \mathrm{confused} \mathrm{with} \mathrm{each} \mathrm{other,} \mathrm{/f} 1 \mathrm{~m} \mathrm{n} \mathrm{p} \mathrm{r/}$ are moderately confused with each other, and $/ \mathrm{j} \mathrm{n} \mathrm{s/} \mathrm{hardly} \mathrm{ever}$ confused with each other.

\section{Words}

Noise also increased the amount of time required for the correct identification of Swedish monosyllabic words. In silence, just over half of the duration of a word was required for identification. This finding is consistent with previous studies using English words. Grosjean (1980) showed that about half of the segments of words were required for word identification. In noise, almost the full duration of words was required for identification in the current study. Table 3 shows that consonant identification in noise was significantly correlated with word identification in noise and HINT performance, which might imply that the misperception of a consonant was misleading for the identification of words in noise. In fact, the incorrect identification of just one consonant or vowel (in consonant-vowel-consonant word format) can lead to the activation of another candidate in the lexicon, and realizing the misperception and finding another candidate takes more time. In summary, noise delays word identification and increases the risk of misidentification, and may make it impossible to identify a word at all. This was also the case in the present study. Not only were the IPs delayed by noise, accuracy was also impeded: about $96 \%$ accuracy in silence versus 35\% in noise (see Table 1). These results are also consistent with previous studies (Chermak and Dengerink, 1981; Studebaker et al., 1999).

\section{Final words in sentences}

The presence of noise delayed final word identification in LP and HP sentences. In silence, highly relevant contextual information seems to prohibit the activation of other lexical candidates even earlier than word-alone presentation. However, the presence of noise resulted in delayed identification of final words even in both LP and HP sentences. These results are in agreement with Aydelott and Bates (2004) who reported that the perceptual clarity of speech signal impacts on the ability to make use of semantic context to aid in lexical processing. They studied how response times to target words in congruent sentences were influenced by low-pass filtering of prior context. Their result showed that low-pass filtering reduced the facilitation of semantic context on identification of target words. The mean IPs for 
final-word identification in LP sentences $(125 \mathrm{~ms}$ in silence and $305 \mathrm{~ms}$ in noise) were found to be even shorter than the mean IPs for isolated words in silence $(462 \mathrm{~ms})$, demonstrating that even low predictable information can speed up decoding of the speech signal (cf. Salasoo and Pisoni, 1985; Van Petten et al., 1999). The accuracy rates for final words in HP and LP sentences in noise were 86 and $67 \%$, respectively, which also is consistent with Kalikow et al. (1977). As Table 1 shows, accuracy in the noise condition was higher for final words in LP sentences $(67 \%)$ than for the identification of isolated words (35\%). We assume that (similar to the identification of isolated words) masking consonants with noise activates other consonants which form words that are still related to the contents of LP sentences, and eliminating them is time consuming. However, because there is some contextual information in LP sentences that excludes some candidates in the mental lexicon, correct identification of final words in LP sentences is accomplished at earlier gates compared to the identification of words in isolation (cf. Ladefoged and Broadbent, 1957).

To conclude, the results from comparing IPs from gated speech stimuli in silence versus noise suggest that less information is available in noise because of masking (e.g., Dorman et al., 1998; Shannon et al., 2004; for a review, see Assmann and Summerfield, 2004). We suppose that the combination of noise with speech stimuli hindered the listener from accessing the detailed acoustic information (in particular for consonants and words), whereas this access to the detailed acoustic information was readily available in a silent condition. As a consequence, noise delays the amount of time required (in other words, necessitates more acoustic information) for correct identification of speech stimuli to occur. In addition, our finding is in agreement with the "active sensing" hypothesis (for a review see Zion Golumbic et al., 2012) which suggests that the brain consistently makes predictions about the identity of the forthcoming stimuli, rather than passively waiting to receive and thereafter identify the stimuli (Rönnberg et al., 2013).

\section{COGNITIVE DEMANDS OF SPEECH PERCEPTION IN SILENCE AND NOISE \\ HINT}

Results showed that HINT performance was correlated with measures of working memory capacity (the reading span test), and attention capacity (PASAT 2). Listeners with better hearing-innoise ability had higher scores in the tests of working memory and attention capacities. This result corroborates the previous studies that reported correlations between sentence comprehension in noise and the reading span test (e.g., Rudner et al., 2009; Ellis and Munro, 2013). Successful performance in the HINT requires filtering out the noise as well as focusing on the target signal, temporarily storing all of the words within sentences, and remembering them. It is therefore reasonable that HINT performance is correlated with the measures of attention and working memory capacities. One of the reasons for this correlation can be found in neuroimaging studies that demonstrate that the activation of auditory (superior temporal sulcus and superior temporal gyrus) and cognitive (e.g., left inferior frontal gyrus) brain areas are provoked during the comprehension of degraded sentences compared to clear speech (Davis et al., 2011; Wild et al., 2012; Zekveld et al., 2012). According to Giraud and Price (2001) and Indefrey and Cutler (2004), the tasks that require extra cognitive processes, such as attention and working memory, activate prefrontal brain areas that include the inferior frontal gyrus. Both stimulus degradation (Wild et al., 2012) and speech-in-noise seem to call on similar neurocognitive substrates (Zekveld et al., 2012). Thus, the observed HINT correlations are in agreement with previous studies.

\section{Consonants}

Better performance in the HINT, reading span test, and PASAT were associated with earlier identification of consonants in noise. Neuroimaging studies have also revealed that ambiguous phoneme identification requires top-down cognitive support from prefrontal brain areas in addition to predominantly auditory brain areas to correctly identify ambiguous phonemes (DehaeneLambertz et al., 2005; Dufor et al., 2007). However, our finding is not in agreement with Cervera et al. (2009) who showed no significant correlations between tests of working memory capacity (serial recall and digit ordering) and consonant identification in noise at $6 \mathrm{~dB}$ SNR. One explanation for this inconsistency may be the fact that we presented the gated consonants at $0 \mathrm{~dB}$ SNR, which is more difficult and cognitively demanding than the task used by Cervera et al. (2009).

\section{Words in isolation}

There was a significant correlation between the IPs of words in noise and scores for the HINT and PASAT 2, suggesting that listeners with better attention capacity and hearing-in-noise abilities identified words in noise earlier than those with poorer abilities. Shahin et al. (2009) degraded words by inserting white noise bursts around the affricatives and fricatives (of words). They found greater activation of the left inferior frontal gyrus during the processing of degraded words, which they suggested was implicated to "repair" the illusion of hearing words naturally when in reality participants had heard degraded words. In our study, it can be concluded that listeners who had better hearing-in-noise and attention capacities were able to repair this "illusion of hearing words naturally" earlier than those with poorer abilities, which resulted in shorter IPs for words in noise. It should be noted that we expected to see a significant correlation between IPs for words in noise and also with the reading span test (working memory capacity). However, there was no significant relationship between IPs for words in noise and test of working memory capacity. One explanation might be that for word identification, we presented the first phoneme of the words and then started the gating paradigm from the second phoneme (in a consonant-vowel-consonant format). In addition, the gate size for word identification was twice as large as for consonants. We therefore assume that this procedure for word identification reduced the demand on working memory for identification of words in noise. With the advantage of hindsight, this potentially important procedural detail should be accounted for in future gating research.

Overall, our findings for the identification of consonants and words in silence and noise are consistent with general predictions 
of the ELU model (Rönnberg et al., 2008, 2013), which suggests that speech perception is mostly effortless under optimum listening conditions, but becomes effortful (cognitively demanding) in degraded listening conditions. Clearly audible signals may not depend as much on working memory and attentional capacities, because they can be implicitly and automatically mapped onto the phonological representations in the mental lexicon.

\section{Final words in sentences}

Our results showed that there were no correlations between the IPs for final words in HP and LP sentences in noise condition and measures of working memory and attention. This finding is consistent with some previous studies which have shown that when listening is challenged by noise, prior contextual knowledge acts as a major source of disambiguation by providing expectations about which word (or words) may appear at the end of a given sentence (cf. Cordillo et al., 2004; Obleser et al., 2007). Hence, it can be assumed that at an equal SNR, the identification of final words in sentences is easier than the identification of consonants and words uttered in isolation; the sentence context makes final word identification less cognitively demanding (i.e., less effortful) than the identification of isolated consonants and words. This result is not in agreement with the original version of the ELU model (Rönnberg, 2003; Rönnberg et al., 2008) in which there was no postulated mechanism for the contextual elimination of lexical candidates. However, in the recent updated version of the ELU model (Rönnberg et al., 2013), the early top-down influence of semantic context on speech recognition under adverse conditions is taken into account. The model suggests that because of the combined semantic and syntactic constraints in a given dialog, listeners may need little information regarding a target signal, if the preceding contextual priming is sufficiently predictive.

In our study, while there were correlations between measures of cognitive tests and the HINT, no significant correlations were observed between cognitive tests and the IPs of final words in (LP and HP) sentences. One possible explanation might be that performance on the HINT requires listeners to remember all of the words in each sentence correctly, at varying SNRs, which taxes working memory (Rudner et al., 2009; Ellis and Munro, 2013). Successful performance in this task requires the short-term decoding and maintenance of masked speech stimuli, and the subsequent retrieval of the whole sentence. However, the identification of final words in sentences simply requires the tracking of incoming speech stimuli, and the subsequent guessing of the final words is based on the sentential context and the first consonant of the final word. This prior context plus initial consonant is likely to reduce cognitive demands, which was presumably lower than that required for the HINT performance. In addition, performance in the HINT was based on $50 \%$ correct comprehension of sentences in noise. As Table 1 shows, the mean accuracy rates in the noise condition for final words in LP and HP sentences were about 67 and $86 \%$, respectively, which are higher than the $50 \%$ correct comprehension rate for sentences in the HINT. Furthermore, the mean SNR for HINT performance in the present study was $-3.1 \mathrm{~dB}$ (Table 2 ), while final words in sentences in noise condition were presented at $0 \mathrm{~dB}$. Thus, it can be concluded that identification in the LP and HP sentences under the noise condition was easier than HINT identification, and as such tapped into the implicit mode of processing postulated by the ELU model. Future studies are needed in order to investigate the correlations between tests of working memory and attention and IPs for final-word identification in sentences at lower SNRs. It is likely that by decreasing the SNR, the demand on working memory and attention capacities will increase even for such sentence completion tasks.

In our study, the PASAT demonstrated a significant correlation with the reading span test, which is in agreement with previous studies (Sherman et al., 1997; Shucard et al., 2004). Interestingly, only the PASAT 2 was correlated with HINT performance and consonant and word identification in noise, whereas the PASAT 3 was not. This probably suggests that the significant relationship with speech perception in noise was related to the attentiondemanding aspect of the task, because PASAT 2 is more paced and taxing. This result is in line with the review by Akeroyd (2008), who argued that only sufficiently taxing cognitive tasks are correlated with speech perception in degraded listening conditions. In Akeroyd (2008), not all cognitive tests yielded significant correlations with noise; only specific measures of cognitive abilities such as working memory (e.g., the reading span test) were correlated with speech-in-noise tasks, whereas general, composite, cognitive measures (like IQ) were not.

Taken together, noise delays the IPs for identification of speech stimuli. In addition, the results suggest that early and correct identification of spoken signals in noise requires an interaction between auditory, cognitive, and linguistic factors. Speech tasks that lack a contextual cue, such as consonants and words presented in isolation, more probably draw on the interaction between auditory and explicit cognitive factors. However, when the perception of speech in noise relies on prior contextual information, or when there is no noise, superior auditory and cognitive abilities are less critical.

\section{CONCLUSIONS}

The identification of consonants, words, and final words in sentences was delayed by noise. The mean correlation between cognitive tests and IPs was stronger for the noisy condition than for the silent condition. Better performance in the HINT was correlated with greater capacities of working memory and attention. Rapid identification of consonants in noise was associated with greater capacities of working memory and attention and also HINT performance; and rapid identification of words in noise was associated with greater capacity of attention and HINT performance. However, the identification of final words in sentences in the noise condition was not demanding enough to depend on working memory and attentional capacities to aid identification. This is presumably due to the facilitation from prior sentential context, lowering the demands on explicit cognitive resources.

\section{ACKNOWLEDGMENTS}

Part of data from the present study has been used in Moradi et al. (2013) in order to compare audiovisual versus auditory gating presentation on IPs and accuracy of speech perception. This research was supported by the Swedish Research Council 
(349-2007-8654). The authors would like to thank Katarina Marjanovic for speaking the recorded stimuli and two reviewers for their insightful comments.

\section{SUPPLEMENTARY MATERIAL}

The Supplementary Material for this article can be found online at: http://www.frontiersin.org/journal/10.3389/fpsyg. 2014.00531/abstract

\section{REFERENCES}

Akeroyd, M. A. (2008). Are individual differences in speech perception related to individual differences in cognitive ability? A survey of twenty experimental studies with normal and hearing-impaired adults. Int. J. Audiol. 47, S53-S71. doi: $10.1080 / 14992020802301142$

Apoux, F., and Healy, E. W. (2011). Relative contribution of target and masker temporal fine structure to the unmasking of consonants in noise. J. Acoust. Soc. Am. 130, 4044-4052. doi: 10.1121/1.3652888

Assmann, P. F., and Summerfield, A. Q. (2004). "The perception of speech under adverse conditions," in Speech Processing in the Auditory System, Vol. 14. Springer Handbook of Auditory Research, eds S. Greenberg, W. A. Ainsworth, A. N. Popper and R. Fay (New York, NY: Springer-Verlag), 231-308.

Aydelott, J., and Bates, E. (2004). Effects of acoustic distortion and semantic context on lexical access. Lang. Cogn. Proc. 19, 29-56. doi: 10.1080/01690960 344000099

Baddeley, A. D., Logie, R., Nimmo-Smith, I., and Brereton, R. (1985). Components of fluent reading. J. Mem. Lang. 24, 119-131. doi: 10.1016/0749596X(85)90019-1

Benichov, J., Cox, L. C., Tun, P. A., and Wingfield, A. (2012). Word recognition within a linguistic context: effects of age, hearing acuity, verbal ability, and cognitive function. Ear. Hear. 32, 250-256. doi: 10.1097/AUD.0b013e31822 f680f

Boehnke, S. E., and Phillips, D. P. (1999). Azimuthal tuning of human perceptual channels for sound location. J. Acoust. Soc. Am. 106, 1948-1955. doi: $10.1121 / 1.428037$

Carlyon, R. P., Cusack, R., Foxton, J. M., and Robertson, I. H. (2001). Effects of attention and unilateral neglect on auditory stream segregation. J. Exp. Psychol. Hum. Percept. Perform. 27, 115-127. doi: 10.1037/0096-1523.27.1.115

Cervera, T. C., Soler, M. J., Dasi, C., and Ruiz, J. C. (2009). Speech recognition and working memory capacity in young-elderly listeners: effects of hearing sensitivity. Can. J. Exp. Psychol. 63, 216-226. doi: 10.1037/a00 14321

Chermak, G. D., and Dengerink, J. (1981). Word identification in quiet and in noise. Scand. Audiol. 10, 55-60. doi: 10.3109/01050398109076162

Colflesh, G. J. H., and Conway, A. R. A. (2007). Individual differences in working memory capacity and divided attention in dichotic listening. Psychon. Bull. Rev. 14, 699-703. doi: 10.3758/BF03196824

Conway, A. R. A., Cowan, N., and Bunting, M. F. (2001). The cocktail party phenomenon revisited: the importance of WM capacity. Psychon. Bull. Rev. 8, 331-335. doi: 10.3758/BF03196169

Cordillo, E. R., Aydelott, J., Matthews, P. M., and Devlin, J. T. (2004). Left inferior prefrontal cortex activity reflects inhibitory rather than faciliatory priming. J. Cogn. Neurosci. 16, 1552-1561. doi: 10.1162/0898929042568523

Cutler, A., Garcia Lecumberri, M. L., and Cooke, M. (2008). Consonant identification in noise by native and non-native listeners: effects of local context. J. Acoust. Soc. Am. 124, 1264-1268. doi: 10.1121/1.2946707

Cutler, A., Smits, R., and Cooper, N. (2005). Vowel perception: effects of nonnative language vs. non-native dialect. Speech Commun. 47, 32-42. doi: 10.1016/j.specom.2005.02.001

Dai, H., Scharf, B., and Buss, S. (1991). Effective attenuation of signal in noise under focused attention. J. Acoust. Soc. Am. 89, 2837-2842. doi: 10.1121/1.400721

Daneman, M., and Carpenter, P. A. (1980). Individual differences in working memory and reading. J. Verbal. Learning. Verbal. Behav. 19, 450-466. doi: 10.1016/S0022-5371(80)90312-6

Davis, M. H., Ford, M. A., Kherif, F., and Johnsrude, I. S. (2011). Does semantic context benefit speech understanding through "top-down" processes? Evidence from time-resolved spare fMRI. J. Cogn. Neurosci. 23, 3914-3932. doi: 10.1162/jocn_a_00084
Davis, M. H., and Johnsrude, I. S. (2007). Hearing speech sounds: top-down influences on the interface between audition and speech perception. Hear. Res. 229, 132-147. doi: 10.1016/j.heares.2007.01.014

Dehaene-Lambertz, G., Pallier, C., Serniclaes, W., Sprenger-Charolles, L., Jobet, A., and Dehane, S. (2005). Neural correlates of switching from auditory to speech perception. Neuroimage 24, 21-33. doi: 10.1016/j.neuroimage.2004.09.039

De Neys, W., Schaeken, W., and D'Ydewalle, G. (2003). "Working memory span and everyday conditional reasoning: a trend analysis," in Proceeding of the twentyfifth Annual Conference of the Cognitive Science Society (Boston, MA), 312-317.

Dorman, M. F., Loizou, P. C., Fitzke, J., and Tu, Z. (1998). The recognition of sentences in noise by normal hearing listeners using simulations of cochlear-implant signal processors with 6-20 channels. J. Acoust. Soc. Am. 104, 3583-3585. doi: 10.1121/1.423940

Dubno, J. R., Horwitz, A. R., and Ahlstrom, J. B. (2005). Word recognition in noise at higher-than-normal levels: decreases in scores and increases in masking. J. Acoust. Soc. Am. 118, 914-922. doi: 10.1121/1.1953107

Dufor, O., Serniclaes, W., Sprenger-Charolles, L., and Démonet, J.-F. (2007). Topdown processes during auditory phoneme categorization in dyslexia: a PET study. Neuroimag 34, 1692-1707. doi: 10.1016/j.neuroimage.2006.10.034

Elliott, L. L., Hammer, M. A., and Evan, K. E. (1987). Perception of gated, highly familiar spoken monosyllabic nouns by children, teenagers, and older adults. Percept. Psychophys. 42, 150-157. doi: 10.3758/BF03210503

Ellis, R. J., and Munro, K. J. (2013). Does cognitive function predict frequency compressed speech recognition in listeners with normal hearing and normal cognition? Int. J. Audiol. 52, 14-22. doi: 10.3109/14992027.2012.721013

Etikregler för humanistisk-samhällsvetenskaplig forskning. (n.d.). Forskningsetiska principer i humanistisk-samhällsvetenskaplig forskning. Antagna av Humanistisksamhällsvetenskapliga forskningsrådet i mars 1990, reviderad version April 1999. [Principles of Research Ethics for Research within the Arts and Social Sciences. Accepted by the Research Council for Arts and Sciences in March 1990, revised version April 1999.] Available online at: http://www.stingerfonden.org/documents/ hsetikregler.pdf (Accessed February 10, 2012).

Foo, C., Rudner, M., Rönnberg, J., and Lunner, T. (2007). Recognition of speech in noise with new hearing instrument compression release settings requires explicit cognitive storage and processing capacity. J. Am. Acad. Audiol. 18, 618-631. doi: 10.3766/jaaa.18.7.8

Giraud, A. L., and Price, C. J. (2001). The constraints functional neuroimaging places on classical models of auditory word processing. J. Cogn. Neurosci. 13, 754-765. doi: 10.1162/08989290152541421

Grant, K. W., and Seitz, P. F. (2000). The recognition of isolated words and words in sentences: individual variability in the use of sentence context. J. Acoust. Soc. Am. 107, 1000-1011. doi: 10.1121/1.428280

Gronwall, D. (1977). Paced Auditory serial addition test: a measure of recovery from concussion. Percept. Mot. Skills 44, 367-373. doi: 10.2466/pms.1977.44.2.367

Grosjean, F. (1980). Spoken word recognition processes and gating paradigm. Percept. Psychophys. 28, 267-283. doi: 10.3758/BF03204386

Hardison, D. M. (2005). Second-language spoken word identification: effects of perceptual training, visual cues, and phonetic environment. Appl. Psychol. 26, 579-596. doi: 10.1017/S0142716405050319

Hällgren, M., Larsby, B., and Arlinger, S. (2006). A Swedish version of the Hearing In Noise Test (HINT) for measurement of speech recognition. Int. J. Audiol. 45, 227-237. doi: 10.1080/14992020500429583

Indefrey, P., and Cutler, A. (2004). "Prelexical and lexical processing in listening" in The Cognitive Neurosciences, 3rd Edn, ed M. S. Gazzaniga (Cambridge, MA: MIT Press), 759-774.

Kalikow, D. N., Stevens, K. N., and Elliott, L. L. (1977). Development of speech intelligibility in noise using sentence materials with controlled word predictability. J. Acoust. Soc. Am. 61, 1337-1351. doi: 10.1121/1.381436

Kane, M. J., and Engle, R. W. (2000). Working memory capacity, proactive interference, and divided attention: limits on long-term memory retrieval. J. Exp. Psychol. Learn. Mem. Cogn. 26, 336-358. doi: 10.1037/0278-7393. 26.2.336

Ladefoged, P., and Broadbent, D. E. (1957). Information conveyed by vowels. J. Acoust. Soc. Am. 29, 98-104. doi: 10.1121/1.1908694

Lidestam, B. (2014). Audiovisual presentation of video-recorded stimuli at a high frame rate. Behav. Res. Methods. 46, 499-516. doi: 10.3758/s13428-013-0394-2

Lively, S. E., Pisoni, D. B., and Goldinger, S. D. (1994). Spoken word recognition: research and theory, in Handbook of Psycholinguistics, ed M. A. Gernsbacher (San Diego, CA: Academic Press), 265-301. 
Lunner, T., Rudner, M., and Rönnberg, J. (2009). Cognition and hearing aids. Scand. J. Psychol. 50, 395-403. doi: 10.1111/j.1467-9450.2009.00742.x

Marslen-Wilson, W. (1987). Functional parallelism in spoken word-recognition. Cognition 25, 71-102. doi: 10.1016/0010-0277(87)90005-9

Mattys, S. L., Davis, M. H., Bradlow, A. R., and Scott, S. K. (2012). Speech recognition in adverse listening conditions: a review. Lang. Cogn. Proc. 27, 953-978. doi: 10.1080/01690965.2012.705006

Mesgarani, N., and Chang, E. F. (2012). Selective cortical representation of attended speaker in multi-talker speech perception. Nature 485, 233-236. doi: 10.1038 /nature 11020

Metsala, J. L. (1997). An examination of word frequency and neighborhood density in the development of spoken-word recognition. Mem. Cogn. 25, 47-56. doi: 10.3758/BF03197284

Miller, G. A., Heise, G. A., and Lichten, W. (1951). The intelligibility of speech as a function of the context of the test materials. J. Exp. Psychol. 41, 329-335. doi: 10.1037/h0062491

Miller, G. A., and Isard, S. (1963). Some perceptual consequences of linguistic rules. J. Verbal. Learning. Verbal. Behav. 2, 217-228. doi: 10.1016/S00225371(63)80087-0

Miller, G. A., and Nicely, P. E. (1955). An analysis of perceptual confusions among some English consonants. J. Acoust. Soc. Am. 27, 338-352. doi: 10.1121/1.1907526

Mondor, T. A., Zatorre, R. J., and Terrio, N. A. (1998). Constrains on the selection of auditory information. J. Exp. Psychol. Hum. Percept. Perform. 24, 66-79. doi: 10.1037/0096-1523.24.1.66

Moradi, S., Lidestam, B., and Rönnberg, J. (2013). Gated audiovisual speech identification in silence vs. noise: effects on time and accuracy. Front. Psychol. 4:359. doi: 10.3389/fpsyg.2013.00359

Nilsson, M., Soli, S. D., and Sullivan, J. A. (1994). Development of the Hearing In Noise Test (HINT) for the measurement of speech reception thresholds in quiet and in noise. J. Acoust. Soc. Am. 95, 338-352. doi: 10.1121/1.408469

Obleser, J., Wise, R. J. S., Dresner, X., and Scott, S. K. (2007). Functional integration across brain regions improves speech perception under adverse listening conditions. J. Neurosci. 27, 2283-2289. doi: 10.1523/JNEUROSCI.466306.2007

Parikh, G., and Loizou, P. C. (2005). The influence of noise on vowel and consonant cues. J. Acoust. Soc. Am. 118, 3874-3888. doi: 10.1121/1.2118407

Petkov, C. I., Kang, X., Alho, K., Bertrand, O., Yund, E. W., and Woods, D. L. (2004). Attentional modulation of human auditory cortex. Nat. Neurosci. 7, 658-663. doi: $10.1038 / \mathrm{nn} 1256$

Phatak, S. A., and Allen, J. B. (2007). Consonant and vowel confusions in speechweighted noise. J. Acoust. Soc. Am. 121, 2312-2316. doi: 10.1121/1.2642397

Poeppel, D., Idsardi, W. J., and van Wassenhove, V. (2008). Speech perception at the interface of neurobiology and linguistics. Philos. Trans. R. Soc. Lond. B Biol. Sci. 363, 1071-1086. doi: 10.1098/rstb.2007.2160

Rabbitt, P. M. (1968). Channel-capacity, intelligibility, and immediate memory. Q. J. Exp. Psychol. 20, 241-248. doi: 10.1080/14640746808400158

Rao, S. M., Leo, G. J., Bernardin, L., and Unverzagt, F. (1991). Cognitive dysfunction in multiple sclerosis: frequency, patterns, and prediction. Neurology. 41, 685-691. doi: 10.1212/WNL.41.5.685

Röer, J. P., Bell, R., Dentale, S., and Buchner, A. (2011). The role of habituation and attentional orienting in the disruption of short-term memory performance. Mem. Cogn. 39, 839-850. doi: 10.3758/s13421-010-0070-z

Rönnberg, J. (1990). Cognitive and communicative functions: the effects of chronological age and "handicap age." Euro. J. Cogn. Psychol. 2, 253-273. doi: $10.1080 / 09541449008406207$

Rönnberg, J. (2003). Cognition in the hearing impaired and deaf as a bridge between signal and dialogue: a framework and a model. Int. J. Audiol. 42, S68-S76. doi: 10.3109/14992020309074626

Rönnberg, J., Arlinger, S., Lyxell, B., and Kinnefors, C. (1989). Visual evoked potentials: relation to adult speechreading and cognitive functions. J. speech. Lang. Hear. Res. 32, 725-735.

Rönnberg, J., Lunner, T., Zekveld, A., Sörqvist, P., Danielsson, H., Lyxell, B., et al. (2013). The Ease of Language Understanding (ELU) model: theoretical, empirical, and clinical advances. Front. Sys. Neurosci. 7:00031. doi: 10.3389/fnsys.2013. 00031

Rönnberg, J., Rudner, M., Foo, C., and Lunner, T. (2008). Cognition counts: a working memory system for ease of language understanding (ELU). Int. J. Audiol. 47, S99-S105. doi: 10.1080/14992020802301167
Rönnberg, J., Rudner, M., Lunner, T., and Zekveld, A. A. (2010). When cognition kicks in: working memory and speech understanding in noise. Noise Health 12 , 263-269. doi: 10.4103/1463-1741.70505

Rudner, M., Foo, C., Rönnberg, J., and Lunner, T. (2009). Cognition and aided speech recognition in noise: specific role for cognitive factors following nine-weeks experience with adjusted compression settings in hearing aids. Scand. J. Psychol. 50, 405-418. doi: 10.1111/j.1467-9450.2009. 00745.x

Rudner, M., Rönnberg, J., and Lunner, T. (2011). Working memory supports listening in noise for persons with hearing impairments. J. Am. Acad. Audiol. 22, 156-167. doi: 10.3766/jaaa.22.3.4

Salasoo, A., and Pisoni, D. (1985). Interaction of knowledge source in spoken word identification. J. Mem. Lang. 24, 210-231. doi: 10.1016/0749-596X(85)90025-7

Sawusch, J. R. (1977). Processing of place information in stop consonants. Percept. Psychophys. 22, 417-426. doi: 10.3758/BF03199507

Shahin, A. J., Bishop, C. W., and Miller, L. M. (2009). Neural mechanisms for illusory filling-in of degraded speech. Neuroimage 44, 1133-1143. doi: 10.1016/j.neuroimage.2008.09.045

Shannon, R. V., Fu, Q.-J., and Galvin, J. (2004). The number of spectral channels required for speech recognition depends on the difficulty of the listening situation. Acta. Otolarygol. Suppl. 552, 1-5. doi: 10.1080/03655230410017562

Sheldon, S., Pichora-Fuller, M. K., and Schneider, B. A. (2008). Priming and sentence context support listening to noise-vocoded speech by younger and older adults. J. Acoust. Soc. Am. 123, 489-499. doi: 10.1121/1.2783762

Sherman, E. M. S., Strauss, E., and Spellacy, F. (1997). Validity of the Paced Auditory Serial Addition Test (PASAT) in adults referred for neuropsychological assessment after head injury. Clin. Neuropsychol. 11, 34-45. doi: $10.1080 / 13854049708407027$

Shinn-Cunningham, B. G., and Best, V. (2008). Selective attention in normal and impaired hearing. Trends. Amplif. 12, 283-299. doi: $10.1177 / 1084713808325306$

Shucard, J. L., Parrish, J., Shucard, D. W., McCabe, D. C., Benedict, R. H. B., and Ambrus, J. (2004). Working memory and processing speed deficits in systemic lupus erythematous as measured by the Paced Auditory Serial Addition Test. J. Int. Neuropsychol. Soc. 10, 35-45. doi: 10.1017/S1355617704101057

Smits, R. (2000). Temporal distribution of information for human consonant recognition in VCV utterances. J. Phon. 27, 111-135. doi: 10.1006/jpho.2000.0107

Snyder, J. S., Alain, C., and Picton, T. W. (2006). Effects of attention on neuroelectric correlates of auditory stream segregation. J. Cogn. Neurosci. 18, 1-13. doi: $10.1162 / 089892906775250021$

Sörqvist, P., and Rönnberg, J. (2012). Episodic long-term memory of spoken discourse masked by speech: what role for working memory capacity. J. Speech. Lang. Hear. Res. 55, 210-218. doi: 10.1044/1092-4388(2011/10-0353)

Sörqvist, P., Stenfelt, S., and Rönnberg, J. (2012). Working memory capacity and visual-verbal cognitive load modulate auditory-sensory gating in the brainstem: toward a unified view of attention. J. Cogn. Neurosci. 24, 2147-2154. doi: 10.1162/jocn_a_00275

Språkbanken (the Swedish Language Bank). (2011). Available online at: http:// spraakbanken.gu.se/ (Accessed November 30, 2011).

Studebaker, G. A., Sherbeco, R. L., McDaniel, D. M., and Gwaltney, C. A. (1999). Monosyllabic word recognition at higher-than-normal speech and noise levels. J. Acoust. Soc. Am. 105, 2431-2444. doi: 10.1121/1.426848

Taylor, W. L. (1953). "Cloze procedure": a new tool for measuring readability. Jour. Q. 30, 415-433.

Tombaugh, T. N. (2006). A comprehensive review of the Paced Auditory Serial Addition Test (PASAT). Arch. Clin. Neuropsychol. 21, 53-76. doi: 10.1016/j.acn.2005.07.006

Troille, E., Cathiard, M.-A., and Abry, C. (2007). "Consequences on bimodal perception of the timing of the consonant and vowel audiovisual flows," in Proceedings of International Conference on Audio-Visual Speech Processing (Hilvarenbeek), 281-286.

Van Petten, C., Coulson, S., Rubin, S., Plante, E., and Parks, M. (1999). Time course of word identification and semantic integration in spoken language. J. Exp. Psychol. Learn. Mem. Cogn. 25, 394-417. doi: 10.1037/0278-7393.25.2.394

Walley, A. C., Michela, V. L., and Wood, D. R. (1995). The gating paradigm: effects of presentation format on spoken word recognition by children and adults. Atten. Percept. Psychophys. 57, 343-351. doi: 10.3758/BF03213059

Wang, M., and Bilger, R. (1973). Consonant confusions in noise: a study of perceptual features. J. Acoust. Soc. Am. 54, 1248-1266. doi: 10.1121/1.1914417 
Wild, C. J., Yusuf, A., Wilson, D. E., Peelle, J. E., Davis, M. H., and Johnsrude, I. S. (2012). Effortful listening: the processing of degraded speech depends critically on attention. J. Neurosci. 32, 14010-14021. doi: 10.1523/JNEUROSCI.152812.2012

Woods, D. L., Yund, E. W., Herron, T. J., and Ua Cruadhlaoich, M. A. I. (2010). Consonant identification in consonant-vowel-consonant syllables in speech-spectrum noise. J. Acoust. Soc. Am. 127, 1609-1623. doi: 10.1121/1.32 93005

Zekveld, A. A., Rudner, M., Johnsrude, I. S., Heslenfeld, D. J., and Rönnberg, J. (2012). Behavioural and fMRI evidence that cognitive ability modulates the effect of semantic context on speech intelligibility. Brain. Lang. 122, 103-113. doi: 10.1016/j.bandl.2012.05.006

Zion Golumbic, E. M., Poeppel, D., and Schroeder, C. E. (2012). Temporal context in speech processing and attentional stream selection: a behavioral and neural perspective. Brain. Lang. 122, 151-161. doi: 10.1016/j.bandl.2011. 12.010
Conflict of Interest Statement: The authors declare that the research was conducted in the absence of any commercial or financial relationships that could be construed as a potential conflict of interest.

Received: 19 February 2014; accepted: 13 May 2014; published online: 02 June 2014. Citation: Moradi S, Lidestam B, Saremi A and Rönnberg J (2014) Gated auditory speech perception: effects of listening conditions and cognitive capacity. Front. Psychol. 5:531. doi: 10.3389/fpsyg.2014.00531

This article was submitted to Auditory Cognitive Neuroscience, a section of the journal Frontiers in Psychology.

Copyright (c) 2014 Moradi, Lidestam, Saremi and Rönnberg. This is an open-access article distributed under the terms of the Creative Commons Attribution License (CC BY). The use, distribution or reproduction in other forums is permitted, provided the original author(s) or licensor are credited and that the original publication in this journal is cited, in accordance with accepted academic practice. No use, distribution or reproduction is permitted which does not comply with these terms. 